\title{
Glucose Control in Mobile Type 1 (Insulin-Dependent) Diabetic Patients by Means of a Semi-automatic Feedback Controlled Insulin Infusion System
}

\author{
K. Piwernetz, R. Renner and K. D. Hepp \\ Oberföhring City Hospital, München, FRG
}

\begin{abstract}
Summary. A portable insulin dosing device (Siemens) was used together with a programmable pocket calculator and a glucose analyzer for short-term adaptation of continuous intravenous insulin infusion to blood glucose alterations. A special algorithm was developed which utilizes a given blood glucose value and the glucose rate of change obtained from two to four consecutive samples as input variables. In contrast to current techniques of feedback-regulation, which require continuous glucose monitoring, intermittent blood sampling allows greater mobility of patients. With the semi-automatic feedback system, euglycaemic control was obtained for 12 -h periods in ten Type 1 (insulin-dependent) diabetic patients (maximum value $9.50 \mathrm{mmol} / 1$, minimum value $2.83 \mathrm{mmol} / 1$ ). Severe hypoglycaemia occurred in no case and additional control by glucose infusion appeared to be unnecessary. Light exercise after termination of insulin dose for standard meals led to glycaemic excursions with a rapid decrease (mean $1.08 \pm 0.09 \mathrm{mmol} / \mathrm{l}$ ),
\end{abstract}

followed by a rebound $(0.59 \pm 0.07 \mathrm{mmol} / \mathrm{l})$ in each patient. The amplitude of these excursions decreased with increasing distance from the peak of the meal dose. Comparison of feedback-control alone with feedback by glucose plus preprogrammed dose $(4 \mathrm{U} / \mathrm{h})$ at the onset of the test meal revealed lower post-prandial glucose levels (post-prandial maximum \pm SEM: $6.49 \pm 0.18$ versus $7.71 \pm 0.79 \mathrm{mmol} / \mathrm{l}$ ) and a lower infusion rate of insulin for the combined regimen (mean postprandial maximum \pm SEM: $8.4 \pm 1.2$ versus $12.0 \pm 0 \mathrm{IU} / \mathrm{h}$ ). The system is useful for programming of portable infusion devices and studies based on euglycaemic control in unrestrained patients.

Key words: Insulin infusion, meal adapted insulin supply, feedback controlled system, algorithm, muscular exercise, Type 1 diabetes.
The current endeavours to achieve glucose homeostasis in diabetic patients with the help of insulin infusion systems were pioneered by Kadish who first used a servomechanism for the control of blood glucose in diabetic subjects [1]. Albisser et al. [2] and Pfeiffer et al. [3] then developed algorithms for their glucose controlled insulin infusion systems which lead to near normoglycaemic control over a longer period of time. Dynamic regulation was introduced in which not only the actual deviation of the blood glucose concentration from a set value, but also the time-dependent change determined a given infusion rate. These algorithms were successively improved $[4,5]$. Other types of algorithms were proposed by Kraegen et al. [6], Kruse-Jarres et al. [7] and Fischer et al. [8], whereby the infusion rate was calculated from the deviation from a set glucose value and the time related change between successive glucose determinations as independent variables.

Feedback-controlled systems are fairly large and generally require immobilization of the patient, thus excluding the important effect of muscular work on glu- cose homeostasis. In a preliminary report Renner et al. presented a simple feedback system which was solely composed of commercially available parts [9]. For this, an algorithm with proportional and differential components was developed where in contrast to previous models $[7,8]$, the variables enter in a nonlinear fashion. Here patients were also immobilized since insulin was infused with a commercial pump from the bed-side. This fairly large apparatus has now been replaced by a miniaturized pump system developed primarily for continuous programmed infusion [10]. The present report describes the use of this new semi-automatic feedback system for blood glucose control in ambulatory diabetic patients.

\section{Patients and Methods}

\section{Patients}

All patients were hospitalized and gave their informed consent for the study. All subjects were Type I (insulin-dependent) diabetics without significant $\mathrm{C}$-peptide response to $1 \mathrm{mg}$ glucagon given IV. Their clini- 
Table 1. Clinical characteristics of ten Type I diabetic patients in the study

\begin{tabular}{|c|c|c|c|c|c|c|}
\hline Patient & Sex & Age (years) & $\begin{array}{l}\% \text { of ideal } \\
\text { body weight }\end{array}$ & $\begin{array}{l}\text { Previous insulin } \\
\text { regimen }(\mathrm{IU})^{\mathrm{a}}\end{array}$ & $\begin{array}{l}\text { Duration of } \\
\text { diabetes (years) }\end{array}$ & Complications \\
\hline 1 & M & 26 & 107 & $44 / 26$ & 3 & - \\
\hline 3 & M & 38 & 102 & $28 / 16$ & 34 & Neuropathy \\
\hline 4 & $\mathrm{~F}$ & 19 & 98 & $30 / 26$ & 5 & - \\
\hline 5 & M & 28 & 100 & $43 / 20$ & 17 & - \\
\hline 6 & M & 43 & 113 & $32 / 24$ & 23 & Neuropathy \\
\hline 8 & $\mathrm{~F}$ & 46 & 112 & $26 / 15$ & 6 & - \\
\hline 9 & $\mathrm{~F}$ & 72 & 102 & $26 / 14$ & 12 & - \\
\hline 10 & M & 50 & 106 & $32 / 18$ & 26 & $\begin{array}{l}\text { Retinopathy } \\
\text { Neuropathy }\end{array}$ \\
\hline
\end{tabular}

\footnotetext{
a Figures denote doses of intermediate acting insulins morning/evening; patient no. 7 received two additional doses of regular insulin
}

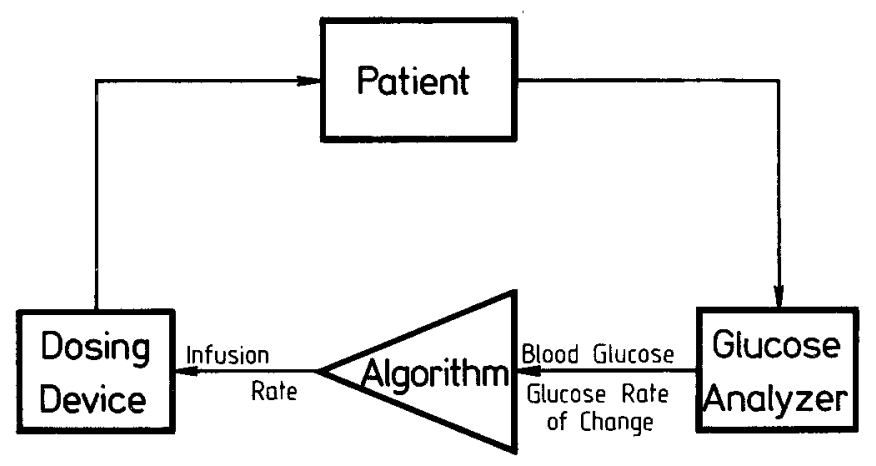

Fig. 1. Schematic diagram of the experimental design as described in the Method section

cal data are shown in Table 1. Patients had no associated diseases and were not receiving any other drugs. On the day before feedback control, the last SC injection of an intermediate acting insulin was given in the morning. At $17.00 \mathrm{~h}$ a catheter was placed in a cubital vein and connected to the minipump for continuous infusion with a basal rate plus a meal-adapted pulse to cover supper and late snack as shown previously [11]. The experiment was started at $08.00 \mathrm{~h}$, blood glucose was determined at 2-30 min intervals. During periods of feedback-controlled infusion, samples for sequential blood glucose determination were obtained from a heparin lock (plastic cannula, Braun Melsungen, Melsungen, FRG) in the contralateral forearm. For each measurement, $50 \mu \mathrm{l}$ of venous whole blood were used which resulted in a blood loss of $1-1.5 \mathrm{ml} / \mathrm{h}$. During the experiment between 08.00 and $14.00 \mathrm{~h}$ the patients received three meals of 530,530 and $650 \mathrm{~kJ}$ containing 48,48 and $60 \mathrm{~g}$ carbohydrates, respectively.

\section{Experimental Design}

Figure 1 shows a schematic representation of the system. The actual blood glucose concentration of the patient was determined with a glucose analyzer. From the time points of blood sampling and the blood glucose values the rate of change of blood glucose was determined. This was done in phases of rapid blood glucose changes by calculating the difference of the last pairs of values of blood glucose and time in order to determine rapidly the new infusion rate. During post-absorptive periods and after exercise, glucose rate of change was determined by regression analysis of the last four pairs of values. Blood glucose and glucose rate of change serve as independent variables to the algorithm for calculation of the infusion rate with a programmable pocket calculator (Texas Instruments T I 59, Dallas, Texas, USA). This rate was then set on the miniaturized portable infusion system which infused the appropriate dose during the next interval.

\section{Glucose Determination}

Venous blood glucose was determined with a commercial glucose analyzer (model 23 A, Yellow Springs Instrument Corporation, Yellow Springs, Ohio, USA). Venous whole blood $(25 \mu \mathrm{l})$ was taken from the cannula and injected directly into the apparatus. Blood glucose is displayed $40 \mathrm{~s}$ after injection in $\mathrm{mmol} / \mathrm{l}$. After another $40 \mathrm{~s}$, the machine was ready for the next test. The value was corrected for the haematocrit which was determined at the start of each experimental period which lasted $12 \mathrm{~h}$. This value was used throughout this time. The variation coefficient was about $1 \%$, base line drifting was $<2 \%$. Under test conditions drifting between two calibrations ( $15 \mathrm{~min}$ interval) was below $0.5 \%$.

\section{The Algorithm}

The present algorithm included the actual glucose concentration and the glucose rate of changes (GRc) as independent variables. In contrast to Kruse-Jarres et al. [7] and Fischer et al. [8], a linear dependency of the infusion rate on GRc was abandoned in favour of a higher infusion rate at low but rising blood glucose concentrations. This reflects the observation that a post-prandial increase in blood glucose cannot be sufficiently compensated by a delayed rise in the infusion rate even with high insulin doses. The algorithm is described by the formula:

$$
\begin{aligned}
& \mathrm{R}=\frac{\mathrm{R}_{\mathrm{o}}}{3} \frac{(\mathrm{F} \cdot \mathrm{GRc}-25 \cdot \mathrm{S} \cdot \mathrm{x}) \mathrm{x}}{25\left(\mathrm{H}+\mathrm{C} \cdot \mathrm{x}_{1} \cdot \mathrm{x}_{1}\right)} \\
& \mathrm{x}=0.9\left(\mathrm{BG}-\mathrm{BG}_{\mathrm{o}}-\mathrm{K}\right) \\
& \mathrm{x}_{1}=0.9\left(\mathrm{BG}-\mathrm{BG}_{\mathrm{o}}\right)
\end{aligned}
$$

where (BG) is the actual blood glucose concentration in $\mathrm{mmol} / \mathrm{1}, \mathrm{GRc}$ the glucose rate of change in $\mathrm{mmol} / \mathrm{l} / \mathrm{h}, \mathrm{BG}_{\mathrm{o}}$ the reference value of the blood glucose concentration in $\mathrm{mmol} / \mathrm{l}$ and $\mathrm{BG}_{0}+\mathrm{K}$ the threshold concentration under which no insulin is infused above a basal rate. $\mathrm{H}$ describes the sensitivity with respect to the onset of the dynamic response at low blood glucose levels; $S$ influences the infusion rate at elevated but falling blood glucose levels; $C$ modifies $S ; F$ dampens the influence of differential regulation at blood glucose levels near $\mathrm{BG}_{\mathrm{o}}$ and small values for GRc. F is described by the formula

$F=\left[18-\frac{25}{G R c} \cdot \exp \left\{-\left(\frac{G R c}{A}\right)^{2}-\left(\frac{B G-B G_{0}}{B}\right)^{2}\right\}\right]$

the exponential function with a negative squared argument (exp$\left.\left(\frac{G R c}{A}\right)^{2}-\left(\frac{B G-B G_{0}}{B}\right)^{2}\right)$ serves to limit the influence of $F$ to the proximity of point $(\mathrm{BG} ; \mathrm{GRc})=\left(\mathrm{BG}_{0} ; 0\right)$. $\mathrm{A}$ and $\mathrm{B}$ are constants. The range of the algorithm is limited by the asymptotes

$\mathrm{A}_{1}: \mathrm{BG}=\mathrm{BG}_{\mathrm{o}}+\mathrm{K}$

$\mathrm{A}_{2}: \mathrm{GRc}=\mathrm{S}\left(\mathrm{BG}-\mathrm{BG}_{\mathrm{o}}-\mathrm{K}\right)$ 


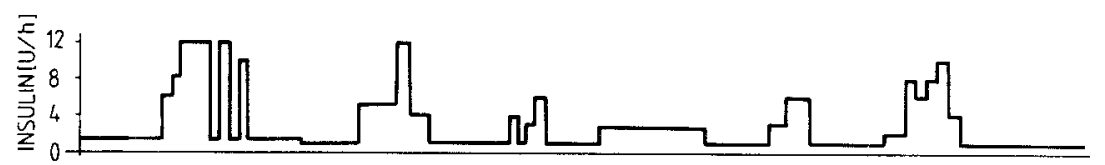

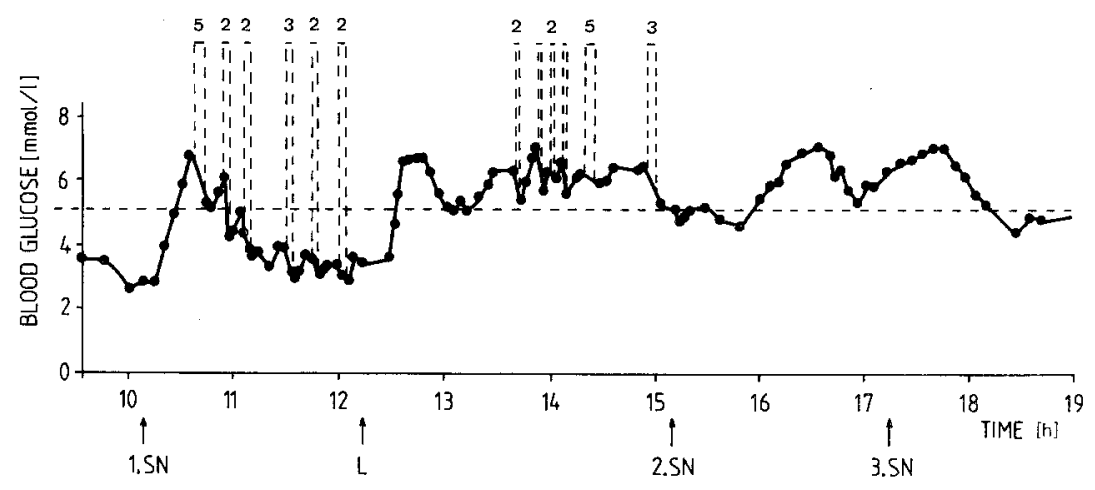

Fig. 2. Continuous semi-automatic insulin infusion in a 26-year-old Type I diabetic patient. Beginning and end of walking exercise periods are indicated by broken vertical lines above the glucose curve with the duration in min. Meals are indicated as follows: $\mathrm{Sn}$ : snack (1. Sn $1840 \mathrm{~kJ}, 2$. Sn $1380 \mathrm{~kJ}, 3$. Sn $920 \mathrm{~kJ})$; L: lunch $(2760 \mathrm{~kJ})$. Basal infusion rate was $1.0 \mathrm{U} / \mathrm{h}$. The start of a meal is indicated by arrows. ----- mean blood glucose: $5.07 \mathrm{mmol} / \mathrm{l}$
Using the following standard values $\mathrm{BG}_{0}=5.56, \mathrm{~K}=-1.11, \mathrm{H}=2.5, \mathrm{~S}$ $=-0.5, \mathrm{C}=0.2, \mathrm{R}_{\mathrm{o}}=12, \mathrm{~A}=1.53, \mathrm{~B}=0.83$ good glucose homeostasis could generally be obtained.

\section{Insulin Infusion Regimes}

On two successive days identical meals were given for lunch during which metabolic control was achieved in five patients according to the following procedure: on day 1 with the start of the meal, the basal rate infusion was substituted by an infusion of $4 \mathrm{U} / \mathrm{h}$. For further management, feedback control was initiated as soon as the permanently evaluated algorithm lead to a higher infusion rate than $4 \mathrm{U} / \mathrm{h}$. This combined programmed/feedback controlled infusion is termed regimen $A$. On day 2 a feedback controlled infusion alone took place and is termed regimen $B$. This sequence for $A$ and $B$ was chosen because of a possible higher sensitivity towards insulin on day 2 due to improved metabolic control. Thus on day 2 the infusion regime was applied which would render the more unfavourable results.

Patients were exercised on a bicycle ergometer after a meal $(1800 \mathrm{~kJ})$ covered by continuous insulin infusion with a total dose of $6 \mathrm{U}$. This dose had been determined previously by glucose-controlled feedback. Thirty minutes after the end of the insulin dose, the patients were subjected to two 15 -min periods of $50 \mathrm{~W}$ each followed by $15-\mathrm{min}$ pauses, and a final $15-\mathrm{min}$ period of $100 \mathrm{~W}$. Blood glucose was determined every $2-3 \mathrm{~min}$.

\section{Statistics}

Results are presented as mean \pm SEM with the exception of Table 2, where SD are shown. Significance of difference was tested with Student's t-test, using paired comparison for feedback control versus the hybrid infusion regimen. In all other cases, the unpaired t-test was applied.

Patients were not randomly assigned to the two infusion regimens $A$ and $B$, allowing regression to mean. The relatively small number of observations was thus subjected to more rigorous criteria.

\section{Results}

\section{Blood Glucose Regulation with Glucose-Controlled Portable Infusion System}

Figure 2 shows blood glucose control over $9 \mathrm{~h}$ in a 26 year old patient with the corresponding rates of insulin infu-
Table 2. Blood glucose regulation with a glucose-controlled portable infusion system in ten Type I diabetic patients

\begin{tabular}{llcc}
\hline Patient & $\begin{array}{l}\text { Mean blood } \\
\text { glucose levels } \\
(\mathrm{mmol} / \mathrm{l})\end{array}$ & $\Delta \mathrm{T}(\mathrm{min})$ & $\Delta \mathrm{G}(\mathrm{mmol} / \mathrm{l})$ \\
\hline 1 & $5.07 \pm 3.77$ & $29.0 \pm 6.2$ & $2.21 \pm 1.07$ \\
2 & $4.15 \pm 1.60$ & $35.2 \pm 5.0$ & $1.85 \pm 0.88$ \\
3 & $5.90 \pm 1.98$ & $40.2 \pm 7.2$ & $2.44 \pm 0.77$ \\
4 & $6.02 \pm 2.92$ & $36.8 \pm 8.4$ & $2.82 \pm 0.43$ \\
5 & $5.32 \pm 1.65$ & $33.4 \pm 10.1$ & $1.98 \pm 0.63$ \\
6 & $5.49 \pm 1.79$ & $55.3 \pm 15.0$ & $2.92 \pm 1.64$ \\
7 & $4.36 \pm 0.80$ & $34.0 \pm 12.0$ & $2.25 \pm 0.17$ \\
8 & $5.38 \pm 1.04$ & $35.3 \pm 12.2$ & $1.74 \pm 0.46$ \\
9 & $6.19 \pm 1.23$ & $*$ & $*$ \\
10 & $4.18 \pm 0.80$ & $*$ & $*$ \\
\hline
\end{tabular}

Results expressed as mean $\pm \mathrm{SD} ; \Delta \mathrm{T}$ is the time between start of a meal and the subsequent maximal blood glucose value, $\Delta \mathrm{G}$ denotes the rise in blood glucose following a meal, as described by Service and Nelson [12]. Both indices were determined for breakfast, morning snack, and lunch. * indicates where $\Delta \mathrm{T}$ and $\Delta \mathrm{G}$ were practically zero

sion which were calculated from the values for blood glucose and glucose rate of change as described in the Methods section. With a reference value $\mathrm{BG}_{\mathrm{o}}$ at $5.56 \mathrm{mmol} / 1$ and a basal rate of $1.0 \mathrm{U} / \mathrm{h}$, the mean glucose level and the glycaemic excursions were kept within the physiological range. Characteristics of glucose regulation under the same conditions are shown for ten diabetic patients in Table 2, which depicts the mean blood glucose over $12 \mathrm{~h}$ and the rise in blood glucose following meals [12], calculated from breakfast, snack and lunch. The data indicate that mean blood glucose was close to the reference value of $5.56 \mathrm{mmol} / 1$ and that the indices $\Delta \mathrm{T}$ and $\Delta \mathrm{G}$ as measures of stability relative to the meals, were within the range of non-diabetic individuals [12].

\section{Effect of Exercise}

As shown in Figure 2, 40 min after the morning snack, the patient was asked to walk without special exertion 

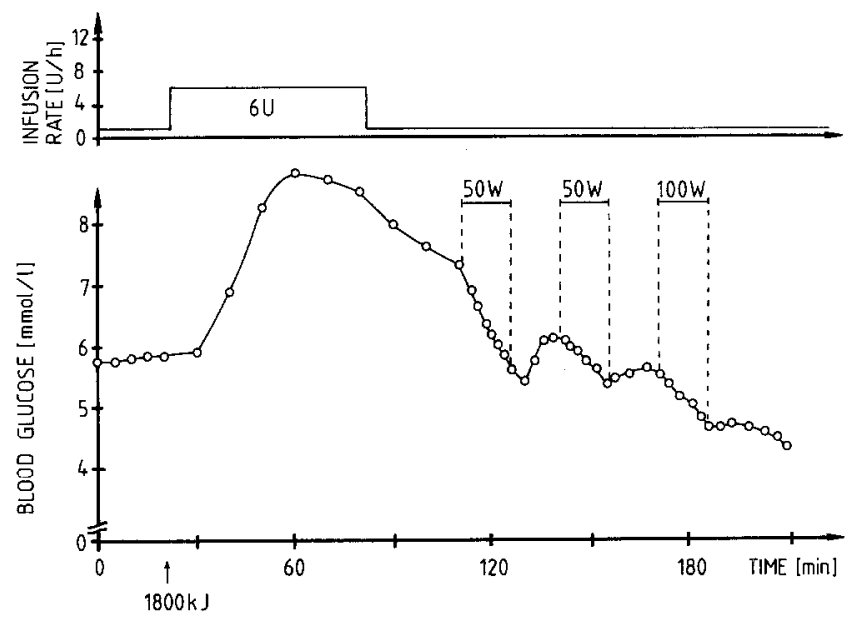

Fig. 3. Glycaemic excursions during bicycle ergometry. Patient was exercised after a morning snack of $1840 \mathrm{~kJ}$ during which he received a square wave of $6 \mathrm{U}$ insulin over $60 \mathrm{~min}$. Duration of exercise was $15 \mathrm{~min}$ at 50 and $100 \mathrm{~W}$
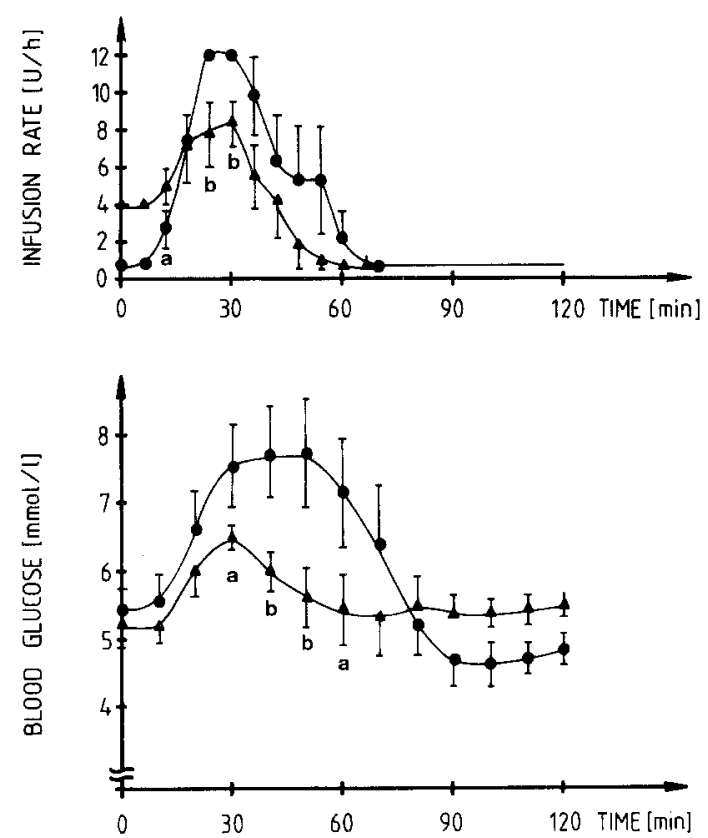

Fig.4. Influence of two different insulin infusion regimes on postprandial glucose curves after lunch. Mean \pm SEM values from five patients. Mean glucose concentration and mean insulin infusion rate: - semi-automatic feedback controlled infusion; $\Delta-\Delta$ semi-automatic feedback control plus programmed insulin dose at the start of the meal $(4 \mathrm{U} / \mathrm{h})$. Significance of difference between curves: a) $p<0.1$; b) $p<0.05$
$(1.1 \mathrm{~m} / \mathrm{s})$ for periods of $2-5 \mathrm{~min}$ between glucose determinations. This lead to a sharp decrease in blood glucose concentration with a short rebound immediately after exercise. When the standard algorithm was applied, these abrupt changes in glucose concentration resulted in pronounced alterations of the infusion rates, as illustrated by the two narrow peaks following the main dose of the morning snack. Moreover, the infusion rates were too high as indicated by the drop in glucose concentration to approximately $2.8 \mathrm{mmol} / 1$. In order to cope with these exercise-induced excursions, the glucose rate of change was calculated by linear regression analysis of the preceding four glucose values. With this modification abrupt changes of the infusion rate could be avoided and hypoglycaemic episodes were observed in no case.

The same patient was then exercised with the help of a bicycle ergometer during the post-prandial phase for three 15 -min periods, as indicated in Figure 3 . The second excursion under the same work load was considerably smaller than the first; doubling the work load to $100 \mathrm{~W}$ only led to similar values as during the previous period. Walking exercises were performed in ten patients and in all cases led to reproducible changes in blood glucose as indicated in Table 3. The amplitude of these excursions became smaller with increased time from the end of the meal.

\section{Comparison of Glucose Controlled Infusion with Programmed Prandial Dose Plus Feedback Control}

Under physiological conditions, insulin is already released at the start of a meal as opposed to the situation with glucose-controlled feedback systems which respond to the rise in blood glucose concentration 10-20 min after the beginning of a meal (Fig. 4). A hybrid infusion regimen, combining feedback control with an initial dose at the start of a test meal, approaches the natural situation. Figure 4 shows the post-prandial blood glucose concentrations and insulin infusion rates under conditions where an infusion rate of $4 \mathrm{U} / \mathrm{h}$ followed by feedback controlled infusion (regimen A) is compared with feedback control alone (regimen B). During the post-prandial phase between 30 and $60 \mathrm{~min}$, regimen $A$ led to significantly lower glucose levels than regimen $B$. The reference value $B G_{0}$ was reached in regimen $A$ after $55 \mathrm{~min}$, in regimen $\mathrm{B}$ not before $75 \mathrm{~min}$. As indicated in Figure 4 , the mean infusion rate in the combined regi-

Table 3. Exercise-induced glycaemic excursions in Type I diabetic patients

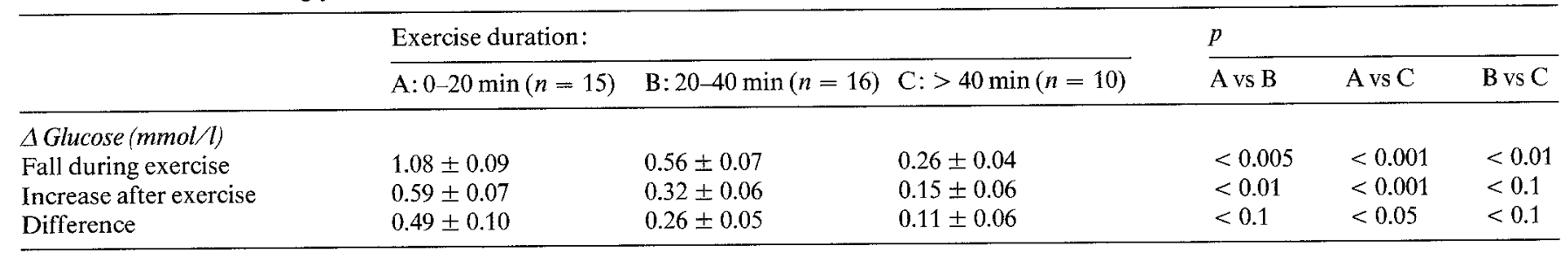

Results are expressed as mean $\pm \operatorname{SEM} n$ : total number of exercise periods. Ten patients walked for 3 min at various time periods after meal dose, resulting in reproducible glycaemic excursions in all cases. 
men was under that of feedback control alone. If one compares the total insulin dose for the two groups, no significant difference was obtained.

\section{Discussion}

The present results show that euglycaemic homeostasis can be achieved with a semi-automatic system. Between monitoring intervals the patient is fully mobile and the influence of muscular exercise can be tested in unrestrained individuals. Compensatory infusion of glucose or glucagon, an additional function of automated glucose-controlled infusion systems $[2,3,6]$, proved to be unnecessary. Although an automatic feedback system with continuous glucose determination is not provided, the term 'feedback regulation' is justified [13].

One practical application is the programming of open-loop infusion devices for continuous intravenous infusion, such as previously performed with bed-side systems but which did not account for muscular activity $[14,15]$. The advantage is that during a period of feedback control, the appropriate meal time doses can be determined for the same infusion device which is left in place for continuous preprogrammed intravenous delivery. This method was used successfully in a number of patients. However, should a suitable glucose sensor be developed, the algorithm described herein would also be appropriate for an implantable feedback system.

It should be stressed that no serious hypoglycaemic reaction was observed. This depends on the selection of the appropriate values for the parameters $S$ and $C$ (see Methods) which determine the decrease in the infusion rate in the presence of elevated but falling blood glucose concentrations.

Long-term application of feedback systems require individual adjustment of any algorithm to a given patient. The present concept contains enough possibilities for an optimal individual regulation. However, limitations are imposed by the maximal infusion rate in patients with a very high insulin requirement. Another serious limitation is the constant requirement of supervision and the disturbance of a patient during the night. This would render the system more suitable for short-term studies. An advantage of two-dimensional algorithms is that they can be displayed graphically [16]. As reported previously [9], regulation can also be performed in a simple way without data processing.

Of special interest are rapid changes in blood glucose following exercise. These exercise induced glycaemic excursions may not enter the calculation of the infusion rate; inclusion could cause hypoglycaemic reactions. This should be considered for the construction of miniaturized portable automatic infusion systems. The nature of these glucose oscillations is not fully understood. Although recently an effect of insulin on plasma volume was published [17], such rapid alterations in haematocrit are unlikely. In this report intravenous administration of
6-8 $\mathrm{U}$ of the hormone in five Type I diabetic patients led to a $8 \%-9 \%$ reduction of the plasma volume [17]. Other experiments, however, showed no change of haematocrit and a transcapillary escape rate of albumin [18]. Therefore this finding of reduced plasma volume with unchanged haematocrit was ascribed to insufficient mixing (pooling) of tracer albumin, probably due to an increase in adrenergic peripheral blood flow. Furthermore, it is known that a marked change in leg blood flow induced by exercise is not accompanied by significant changes in leg haematocrit [19]. Therefore changes in haematocrit do not seem to account for the observed glucose alterations during exercise. The decrease in amplitude with the time distance from an elevated insulin dose suggests a relationship to receptor bound insulin.

A combined programmed/feedback controlled infusion regimen is superior to a feedback system alone. By the initial demand of more insulin at the start of the meal the physiological cephalic phase of the insulin secretion [20] is imitated. Therefore during the very early postprandial phase sufficient insulin is present to induce pronounced anabolic reactions. Thus compared with feedback regulation alone, a lower mean glucose concentration was obtained, and it may be derived from the decrease in infusion rates that this kind of insulin supply offers a possibility to reduce peripheral hyperinsulinaemia. Similar conclusions were reached by Kraegen et al. [21] with a bed-side computer-assisted infusion system.

\section{References}

1. Kadish AH (1963) Automation control of blood sugar. A servomechanism for glucose monitoring and control. Trans Am Soc Artif Organs 9: 363-367

2. Albisser AM, Leibel BS, Ewart TG, Davidovac Z, Botz CK, Zingg W (1974) An artificial endocrine pancreas. Diabetes 23:389-396

3. Pfeiffer EF, Thum C, Clemens AH (1974) The artificial beta-cell. A continuous control of blood sugar by external regulation of insulin infusion (glucose controlled insulin infusion system). Horm Metab Res 6: 339-342

4. Botz CK (1976) An improved control algorithm for an artificial beta-cell. IEEE Trans Biomed Eng 23:252-255

5. Kerner W, Thum C, Tamas jun. G, Beischer W, Clemens AH, Pfeiffer EF (1976) Attempt to perfect normalization of glucose tolerance test by artificial beta-cell. Horm Metab Res 8: 256-261

6. Kraegen EW, Campbell LV, Chia YO, Meler H, Lazarus L (1977) Control of blood glucose in diabetics using an artificial pancreas. Aust NZJ Med 7:280-286

7. Kruse-Jarres JD, Bresch W, Lehmann U (1979) Steueralgorithmus für die extrakorporale Blutglucoseregulierung. J Clin Chem Clin Biochem 17: 465-469

8. Fischer U, Jutzi E, Bombor H, Freyse EJ, Salzsieder E, Albrecht G, Besch W, Bruns W (1980) Assessment of an algorithm for the artificial beta-cell using normal insulin-glucose relationship in diabetic dogs and men. Diabetologia 18:97-107

9. Renner R, Piwernetz K, Hepp KD, Mehnert H (1979) Optimizing open-loop systems for continuous intravenous insulin therapy. In: Waldhäusl W, Alberti KGMM (eds) $10^{\text {th }}$ Congress of the International Diabetes Federation, Excerpta Medica International Congress Series, Amsterdam, Oxford 481: 194 (Abstract)

10. Prestele K, Franetzki M, Kresse H (1980) Development of pro- 
gram-controlled portable insulin delivery devices. Diabetes Care 3 : 362-368

11. Hepp KD, Renner R, Piwernetz K, Mehnert H (1980) Control of insulin dependent diabetes with portable miniaturized infusion systems. Diabetes Care 3: 309-313

12. Service JF, Nelson RL (1980) Characteristics of glycemic stability. Diabetes Care 3: 58-62

13. German Committee for Engineering Norms (1968) Normblatt DIN 19226. Beuth-Vertrieb, Berlin

14. Service FJ, Rizza RA, Westland RE, Hall LD, Nelson RL, Haymond MW, Clemens AH, Gerich JE (1980) Considerations for the programming of an open-loop insulin infusion device from the $\mathrm{Bi}$ ostator glucose controller. Diabetes Care 3: 278-284

15. Irsigler K, Kritz H, Kaspar L, Brändle J, Koller W, Franetzki, M (1979) Preprogrammed insulin infusion with a portable pump system. In: Hepp KD, Kerner W, Pfeiffer EF (eds) Feedback-controlled and preprogrammed insulin infusion in diabetes mellitus, Hormones and Metabolic Research Suppl. 8, pp.193-197

16. Piwernetz K, Renner R, Hepp KD (1981) Determination of an adequate dosing scheme for continuous insulin infusion in mobile diabetics. In: Irsigler K, Kunz, KN, Owens DR, Regal H (eds) New approaches to insulin therapy, MTP-Press, Lancaster, pp 47-54

17. Gundersen HJG, Christensen NJ (1977) Intravenous insulin causing loss of intravascular water and albumin and increased adrenergic nervous activity in diabetes. Diabetes 26: 551-557
18. Parving HH, Noer I, Deckert T, Lassen NA (1979) Intravenous insulin has no effect on transcapillary escape rate of albumin and on plasma volume in short-term juvenile diabetics. Diabetes 28: 282-286

19. Larsen OA (1963) The hematocrit of the lower extremity as a model of the so-called collagen diseases. Canad Med Ass J 88:442-452

20. Jeanrenaud B, Berthoud HR, Bereiter DA, Rohner-Jeanrenaud F, Hochstrasser AC (1980) Ventromedial, ventrolateral hypothalamus and other CNS sites and their relationship with the activity of the endocrine pancreas. In: Waldhäusl WK (ed) Diabetes 1979, Excerpta Medica, Amsterdam, Oxford, Princeton, pp 51-56

21. Kraegen EW, Chipps D, Chisholm DJ, Bell D, Zelenka G, Lazarus L (1979) Insulin delivery during meals to diabetics using computerassisted insulin delivery systems. In: Waldhäusl W, Alberti KGMM (eds) Tenth Congress of the International Diabetes Federation, Excerpta Medica International Congress Series, Amsterdam, Oxford 481:127

Received: 3 September 1981

and in revised form: 9 March 1982

Dr. R. Renner

Oberföhring City Hospital

Oberföhringer Str. 156

8000 München 81, FRG 